\title{
Lactoferrin - A Potential Anabolic Intervention in Osteoporosis
}

\author{
Dorit Naot ${ }^{1}$, Kate Palmano ${ }^{2}$ and Jillian Cornish ${ }^{1}$ \\ 1 University of Auckland \\ ${ }^{2}$ LactoPharma Consortium, Fonterra Research Centre \\ New Zealand
}

\section{Introduction}

Osteoporosis or porous bone was first described by Fuller Albright approximately 70 years ago as having "too little bone in the bone". Bone tissue is maintained throughout life by being continually replaced and in osteoporosis bone resorption exceeds bone formation resulting in bone loss. The majority of current treatments for osteoporosis are antiresorptive, decreasing osteoclast activity and preventing further bone loss. Therapeutic agents that activate osteoblasts and increase bone formation have the potential benefit of restoring bone rather than only preventing further deterioration, but only a small number of safe anabolic therapies are currently available. Milk is a rich biological fluid that contains many growth factors and provides nutrition at a time of very rapid skeletal growth and development in the neonate, and was therefore considered as a possible source of factors with anabolic effects on bone. Investigations of fractions of whey proteins extracted from milk identified lactoferrin as a bone-active factor. Lactoferrin is an iron-binding glycoprotein which as well as being present in milk is found in other epithelial secretions. It is a pleiotropic factor with potent antimicrobial and immunomodulatory activities, and shows anabolic effects in bone at physiological concentrations. In a number of recent studies in humans and experimental animals dietary lactoferrin supplementation improved bone mineral density, bone markers and bone strength. The current chapter discusses the structure and function of lactoferrin, the bone-effects of lactoferrin in vitro and in vivo, and the potential use of lactoferrin for the improvement of bone health.

\section{Lactoferrin}

Lactoferrin is a multifunctional glycoprotein that was originally identified in bovine milk and first isolated from both human and bovine milk five decades ago (Groves et al. 1963). Lactoferrin is produced by mucosal epithelial cells and is present in very high concentrations in milk and colostrum, and in lower concentrations in mucosal secretions, including tears, saliva, nasal and bronchial secretions, bile and gastrointestinal fluids. Lactoferrin is also a major constituent of the secondary granules of neutrophilic leukocytes, and its serum level in healthy subjects is within the range of $1-10 \mu \mathrm{g} / \mathrm{mL}$ (Caccavo et al. 1999). 


\subsection{Molecular structure}

Lactoferrin is a non-haem iron-binding protein which belongs to the transferrin family of iron-transport proteins. It is a highly cationic monomeric glycoprotein with an isoelectric point of about 8.7 (Moguilevsky et al. 1985) and consists of about 690 amino acid residues folded into two homologous lobes, the so-called N-and C-lobes, which are linked by a 10-15 residue alpha helical peptide (Baker \& Baker 2005). There is a high degree of homology between lactoferrin from various species with bovine and human lactoferrin sequence identity being 69\% (Pierce et al. 1991).

\subsubsection{Iron binding and glycosylation}

Each of the lactoferrin lobes contains a virtually identical iron-binding pocket, into which a trivalent iron cation $(\mathrm{Fe} 3+)$ can be reversibly co-ordinated. The metal binding sites are highly conserved for all lactoferrins and transferrins thus far characterised (Baker \& Baker 2009). Lactoferrin molecules can exist in several states whereby there is complete, partial (in either one of the two sites) or no occupancy of the two iron-binding sites. Lactoferrin isolated from both human and bovine milk has a low iron saturation, generally reported between $10-25 \%$ (Bezwoda \& Mansoor 1989). In vitro, iron can be removed from lactoferrin to yield the ironfree or 'apo' form, or alternatively, lactoferrin can be loaded with iron to yield the fully ironbound or 'holo' form. Although other di- and trivalent transition metal ions such as Mn3+, $\mathrm{Co} 3+, \mathrm{Cu} 2+$ and $\mathrm{Cr} 3+$ and even larger cations such as lanthanides (Smith et al. 1994) can be co-ordinated into the metal binding pocket, iron appears to be the natural ligand as it has optimal co-ordination and a very high binding affinity (Baker 1994). Nevertheless, lactoferrin may have a physiological role in binding trace amounts of other elements as manganese in milk is found exclusively associated with lactoferrin (Lonnerdal et al. 1985).

All lactoferrins are glycosylated, but the number and location of glycosylation sites varies from species to species, and is also tissue specific (Derisbourg et al. 1990). Differentially glycosylated lactoferrins appear to have similar biophysical and functional properties suggesting minimal structural impact of glycosylation (Moguilevsky et al. 1985).

\subsubsection{Interactions with other molecules}

The highly basic nature of lactoferrin is contributed mainly by surface-exposed N-terminal domains containing clusters of highly basic residues which are capable of binding proteins such as ceruloplasmin (Vasilyev 2010) and osteopontin (Yamniuk et al. 2009). These cationic domains also confer on lactoferrin the ability to bind to many other anionic molecules including heparin, glycosaminoglycans, DNA, and various cell surface molecules (He \& Furmanski 1995; Mann et al. 1994; van Berkel et al. 1997).

\subsection{Physiological function}

\subsubsection{Anti-microbial activity}

The highly cationic nature of lactoferrin and its high affinity iron binding are implicated in the anti-microbial function of this glycoprotein. Thus, iron sequestration in sites of bacterial infection deprives the bacteria of this essential nutrient, creating a bacteriostatic effect (Gonzalez-Chavez et al. 2009; Jenssen \& Hancock 2009). Lactoferrin has bactericidal effect as well, as it interacts directly with anionic molecules on the cell surface, causing cell lysis. In Gram-negative bacteria, lactoferrin interacts directly with LPS, causing its release from the cell wall and increasing the external membrane permeability, which results in cell lysis. In 
Gram-positive bacteria lactoferrin damages the cell through direct interactions with lipoteichoic acid and other anionic surface molecules. Iron sequestration and interactions with anionic molecules are also the main mechanisms responsible for lactoferrin's activity against fungus and parasite infections. Lactoferrin has been described as an antiviral agent that affects a broad range of RNA and DNA viruses that infect humans and animals (Gonzalez-Chavez et al. 2009). Although the antiviral mechanisms of lactoferrin have not been well characterised yet, one of the most widely accepted hypothesis is that lactoferrin blocks viral receptors on the cell surface, and in particular heparin sulphate, preventing contact between the virus and the target cell.

\subsubsection{Modulation of the immune response and inflammation}

Lactoferrin is a modulator of both the innate and acquired immune systems. Following the penetration of a microbe into a tissue, cells of the innate immune system release proinflammatory cytokines, including interleukins 1 and 6 (IL-1, IL-6) and tumor necrosis factor-alpha (TNF-a), which increase the permeability of blood vessels enabling the recruitment of circulating neutrophils to the site of infection. The release of neutrophil granule content creates very high local concentrations of lactoferrin. Apart from direct antimicrobial activity, lactoferrin interacts with cells of the innate immune systems as well as with cells of the adaptive immunity; regulating their recruitment, proliferation, differentiation and activation (Legrand et al. 2006; Legrand \& Mazurier 2010).

In different experimental systems, lactoferrin acts as either an anti-inflammatory or a proinflammatory factor. The anti-inflammatory activity of lactoferrin is attributed to its ability to bind free iron and exogenous proinflammatory bacterial components, such as LPS and their receptors (Legrand et al. 2005). Thus, lactoferrin activity as an iron scavenger prevents the formation of free radicals, which trigger oxidation processes and tissue damage, while binding to proinflammatory molecules inhibits the activation and recruitment of immune cells to the inflamed tissue. An additional mechanism implicated in the anti-inflammatory activity of lactoferrin has been recently described in apoptosis, the process of noninflammatory programmed cell death. Bournazou et al. (Bournazou et al. 2009; 2010) discovered that apoptotic cell of diverse lineages synthesize and secrete lactoferrin, which selectively inhibits the migration of granulocytes but not mononuclear phagocytes. This selective migration allows for the swift phagocytosis of the dying cells by the mononuclear cells without initiating an inflammatory response. Subsequently, lactoferrin was also found to have an inhibitory effect on eosinophil migration (Bournazou et al. 2010). A number of other studies describe the proinflammatory activities of lactoferrin. As a factor that induces inflammation, lactoferrin has been shown to promote cell motility, superoxide production, release of nitric oxide, release of the proinflammatory cytokines TNF- $\alpha$ and IL-8 and phagocytosis (Gahr et al. 1991; Legrand \& Mazurier 2010; Shinoda et al. 1996; Sorimachi et al. 1997).

\subsubsection{Iron homeostasis and antioxidation}

Although lactoferrin is an iron-binding protein and has been shown to influence iron status in pregnant women (Paesano et al. 2009) it is generally thought not to have a central role in iron-transport and homeostasis, unlike the transferrins. Nevertheless it does appear to have some role in iron regulation at local sites of inflammation and infection (Brock 2002) and 
iron sequestration is an important part of its role both as an antioxidant and antibacterial agent (Baldwin et al. 1984; Jenssen \& Hancock 2009). In respect of iron-binding, lactoferrin is functionally different from transferrin as it retains iron to a much lower $\mathrm{pH}$, giving it a more potent iron-withholding ability (Baker \& Baker 2009). Although the antioxidant properties of lactoferrin are generally related to removal of free iron which otherwise reacts with reactive oxygen species (ROS) to form damaging hydroxyl radicals (Matsue et al. 1995; Raghuveer et al. 2002) a recent report suggests that apo- and holo bovine-lactoferrin have equal ability to act as antioxidants by scavenging ROS (Kanwar et al. 2011). This radical quenching ability, akin to antioxidant vitamins, is seemingly iron independent.

\subsubsection{Bioactive peptides derived from lactoferrin}

Functional cationic peptides with potent antibacterial activity, such as lactoferricin and lactoferrampin, can be derived from the N-terminal domain of lactoferrin by hydrolysis (Bellamy et al. 1992) or synthetic chemistry (van der Kraan et al. 2004), respectively. Lactoferrin can be degraded by digestive enzymes (Brock et al. 1976; Troost et al. 2001) and the functional peptide lactoferricin is likely to be formed in the gut by the action of pepsin. Lactoferrin 'half molecules' consisting of either the N-lobe or C-lobe can be generated by proteolysis or by recombinant technology (Baker \& Baker 2005; Kim et al. 2006). These are useful as tools to probe for site-specific functionality or interactions. For example, the antiherpes virus activity of lactoferrin has been shown to be mediated mainly by the N-lobe (Siciliano et al. 1999) while simple sugars have been shown to interact with the C-lobe through a common recognition site (Mir et al. 2010).

\section{The activity of lactoferrin in bone}

\subsection{Osteoblasts}

\subsubsection{In vitro studies of lactoferrin activity in osteoblasts}

Lactoferrin potently induces proliferation of primary osteoblasts and osteoblastic-cell lines and increases osteoblast differentiation at physiological concentrations (Fig 1A) (Cornish et al. 2004; Takayama \& Mizumachi 2008, 2009). In 3-week cultures of primary fetal rat osteoblasts lactoferrin dose-dependently increased osteoblast differentiation with increases in bone matrix deposition and the number of mineralized bone nodules formed (Fig 1B) (Cornish et al. 2004). In addition, lactoferrin decreased apoptosis induced by serum withdrawal in primary rat osteoblasts (Fig 1C) (Cornish et al. 2004) and in the human osteoblastic cell line SaOS2 (Grey et al. 2006). These effects on both the proliferation and survival of osteoblasts are profound, being far greater than those observed in response to several established osteoblast growth factors studied in the same in vitro assays, such as epidermal growth factor, transforming growth factor- $\beta$, parathyroid hormone, amylin or insulin. These factors increase thymidine incorporation in primary osteoblast cultures by only $20-30 \%$ (Cornish et al. 1999) whereas lactoferrin produces three- to five-fold increments (Cornish et al. 2004). This growth stimulating potency is complemented by the capacity of lactoferrin to substantially reduce osteoblast apoptosis, which again, is much more dramatic than the effects seen with other factors, such as insulin growth factor- 1 (IGF1) which maximally decreases apoptosis by $50 \%$ (Cornish et al. 2000) compared to $70 \%$ with lactoferrin (Cornish et al. 2004). 

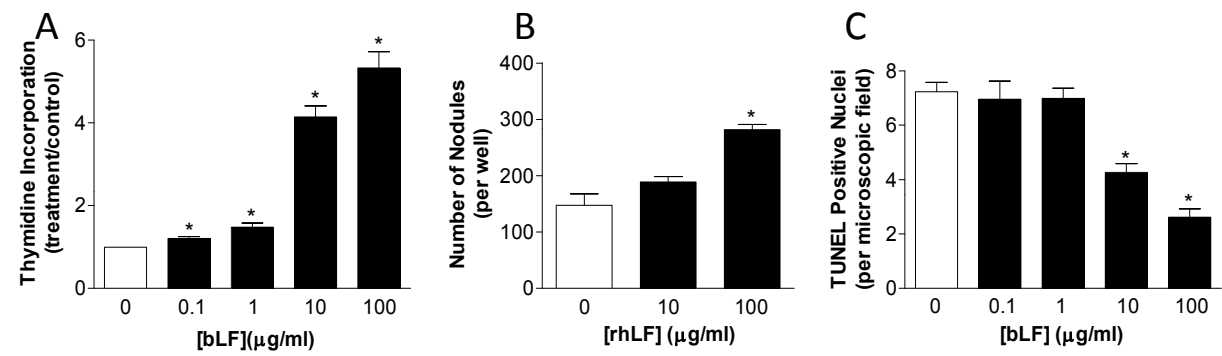

Fig. 1. Lactoferrin stimulates osteoblast proliferation, differentiation and survival in vitro

Thus, lactoferrin acts to expand the pool of pre-osteoblastic cells by exerting mitogenic and anti-apoptotic effects, as well as promoting differentiation of precursors to produce a more mature osteoblastic phenotype capable of promoting bone matrix deposition and mineralization.

\subsubsection{Local injection model}

The activities of lactoferrin on osteoblasts demonstrated in vitro are likely to contribute to the potent effects on bone formation seen in vivo after administration of lactoferrin, even with a very short-term exposure (Fig 2) (Cornish et al. 2004). The bone growth resulting from local lactoferrin injection is considerably greater than that found previously in response to factors such as insulin, amylin, adrenomedullin and C-terminal PTH-related peptide (Cornish et al. 1996; 1997a; 1997b). It is qualitatively different from the effects of PTH in this model, which produces a powerful stimulation of bone resorption in addition to its effect on formation (Cornish et al. 1995). This anabolic potency suggests that lactoferrin should be further explored as a therapy for osteoporosis that can restore skeletal strength.

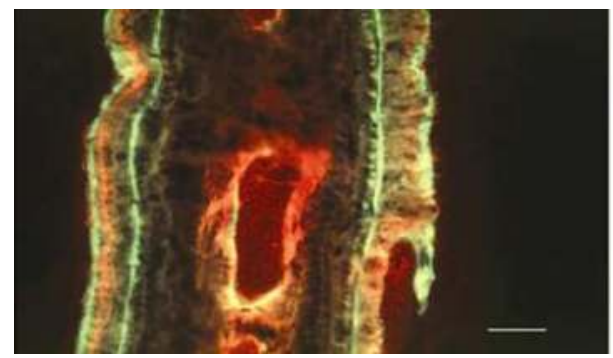

A

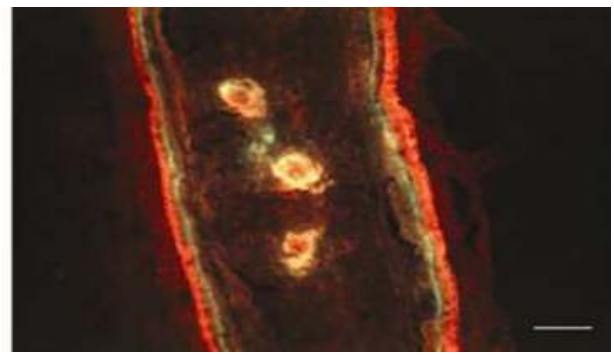

B

Fig. 2. Photomicrographs of calvariae from animals treated with lactoferrin (A) and vehicle (B) for 5 days. Fluorochrome labels used: green, calcein; red, alizarin. Horizontal bar, $50 \mu \mathrm{m}$. (Figure reproduced with kind permission. Cornish J., et al. Lactoferrin is a potent regulator of bone cell activity and increases bone formation in vivo. Endocrinology 145(9): 2004, 43664374. Copyright 2004, The Endocrine Society.) 


\subsubsection{Signalling pathways activated by lactoferrin in osteoblasts}

The downstream pathways activated by lactoferrin are largely unknown, although a number of lactoferrin receptors have been described. A specific lactoferrin receptor was cloned from the human intestine (Kawakami \& Lonnerdal 1991) but this receptor is not expressed in all cell types that respond to lactoferrin and we have been unable to detect the mRNA in osteoblastic cells (Naot, unpublished data). Proteins that can bind and induce endocytosis of lactoferrin are nucleolin (Legrand et al. 2004) as well as low-density lipoprotein receptor-related proteins 1 and 2 (LRP1 and LRP2) (Ji \& Mahley 1994; Willnow et al. 1992). LRP1 and LRP2 are expressed in osteoblastic cells and LRP1 is at least partially responsible for lactoferrin's mitogenic effects in osteoblasts (Grey et al. 2004). As lactoferrin complexes with LRP1, extracellular signal-regulated kinase (ERK) signalling pathway is upregulated. In addition, lactoferrin upregulates phosphoinositide 3-kinase-dependent Akt signalling but this is in an LRP-independent manner. Lactoferrin's anti-apoptotic activity in osteoblasts is independent of both these two signalling pathways.

In primary osteoblasts, lactoferrin induces a transient, dose-dependent increases in the transcription levels of IL-6, IL-11, the pro-inflammatory factor prostaglandin-endoperoxide synthase 2 (Ptgs2, encoding for the enzyme cyclooxygenase-2, COX-2) and the transcription factor nuclear factor of activated T-cells (Nfatc1). The activity of COX-2 to produce and secrete prostaglandin E2 and the activity of NFATc1 to promote transcription from NFAT consensus elements are also induced by lactoferrin. Moreover, COX-2 and NFATc1 act as mediators of the proliferative effect of lactoferrin in osteoblasts, as inhibition of their activities significantly reduces lactoferrin-induced thymidine incorporation (Naot et al. 2011). Recently, Nakajima et al demonstrated that lactoferrin induces synthesis of angiogenic factors by osteoblasts. In murine osteoblast-like MC3T3-E1 cells and primary murine osteoblasts lactoferrin, purified from milk, increased mRNA expression of vascular endothelial growth factor (VEGF) and fibroblast growth factor-2 (FGF2) in a p44/p42 MAP kinase-dependent manner (Nakajima et al. 2011). A summary of some of the signalling pathways'activated by lactoferrin in osteoblasts is presented in Figure 3.

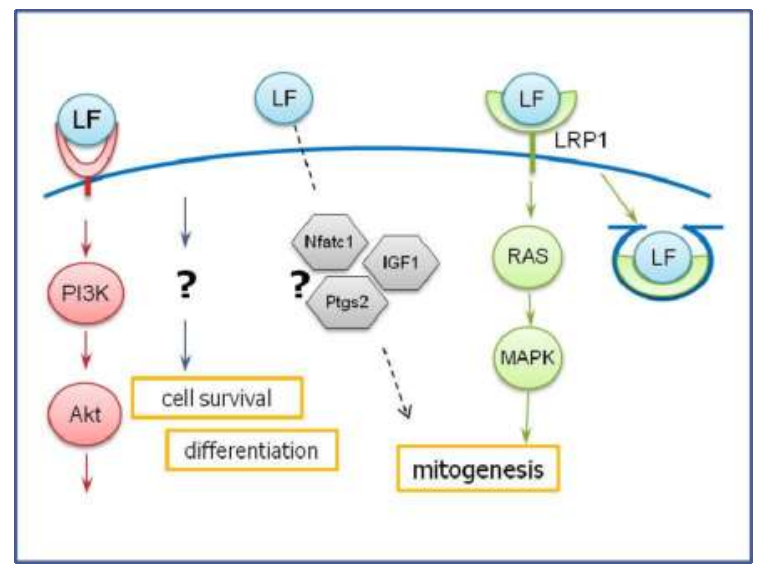

Fig. 3. Mechanisms of action of lactoferrin in osteoblasts. Figure reproduced with kind permission from Springer Science+Business Media: (Biometals, Lactoferrin as an effector molecule in the skeleton, 23, 2010, 425-430, Cornish, J. \& Naot, D. Figure 1.) 


\subsubsection{Lactoferrin effects on early stages of osteogenic differentiation}

Lactoferrin supports osteogenic differentiation in mesenchymal pluripotent cells whilst reducing adipogenic differentiation. In the pluripotent mesenchymal cell line, $\mathrm{C} 2 \mathrm{C} 12$, analyses of expression levels of mRNA and proteins indicated an induction of osteoblastic and chondroblastic differentiation markers and a reduction in myoblastic and adipocytic markers (Yagi et al. 2009). We have identified that lactoferrin reduces adipogenic differentiation in KUSA4b10 cells, a mouse mesenchymal progenitor cell-line capable of developing into adipogenic or osteogenic cell lineages (Fig 4). Lactoferrin has also been found to promote the proliferation and osteogenic differentiation of human adipose stem cells (Ying et al. 2011). The activity of lactoferrin to support osteogenic differentiation whilst reducing adipogenic differentiation could be a promising approach for enhancing osteogenic capacity of cell-based construction in bone tissue engineering.

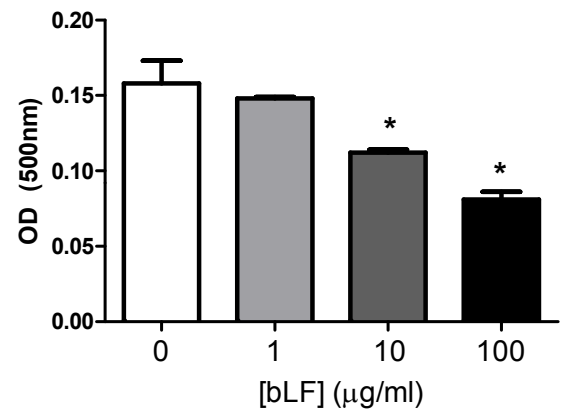

Fig. 4. Lactoferrin reduces adipogenic differentiation in KUSA4b10 cells as measured by Oil Red O release detected in a spectrophotometer at an optical density (OD) of 500nm.

\subsection{Osteoclasts}

In comparison with actions of lactoferrin on osteoblasts, its osteoclasts effects are strikingly different, in that it produces an almost total arrest of osteoclastogenesis in mouse bone marrow cultures (Fig 5) (Cornish et al. 2004). Reduced bone-resorbing activity was also demonstrated by Lorget et al, who used bovine lactoferrin in a rabbit mixed bone cell culture (Lorget et al. 2002). The mechanisms implicated in the inhibitory effect of lactoferrin on bone resorption are only partially understood. In the rabbit bone cell cultures, lactoferrin inhibited the development of mature osteoclasts by a mechanism independent of the receptor activator of NF-KB (RANK)/RANK-ligand (RANKL)/osteoprotegerin (OPG) system. In the mouse bone marrow cultures, lactoferrin reduced RANKL expression, which could in part explain the inhibition of osteoclastogenesis, although this was counterbalanced by the effects of lactoferrin to also inhibit expression of OPG (Cornish et al. 2004). As the RANK/RANKL/OPG pathway does not appear to play a major role in mediating the inhibitory effect of lactoferrin on osteoclast formation, the possibility of a direct effect on osteoclasts has been investigated. In RAW264.7 cells, which differentiate into osteoclasts in vitro in the absence of osteoblasts or stromal cells, lactoferrin inhibited RANKL-induced osteoclastogenesis in a dose-dependent manner, demonstrating a direct effect on osteoclasts (Cornish \& Naot 2010). This effect of lactoferrin was not blocked by an inhibitor of LRP1, indicating that LRP1 is not the receptor that mediates the direct inhibition of 
osteoclastogenesis by lactoferrin (Cornish \& Naot 2010). It should be noted that lactoferrin has a capacity to inhibit the survival of progenitor cells in the bone marrow, implying that it might also act earlier in osteoclast development (Hangoc et al. 1991). In contrast to its inhibitory effect on osteoclast development, lactoferrin had no effect on bone resorption by isolated mature osteoclasts nor in organ cultures which also detect mature osteoclast activity (Cornish et al. 2004). Thus, lactoferrin inhibits bone resorption by reducing the number of osteoclasts formed from precursor cells.

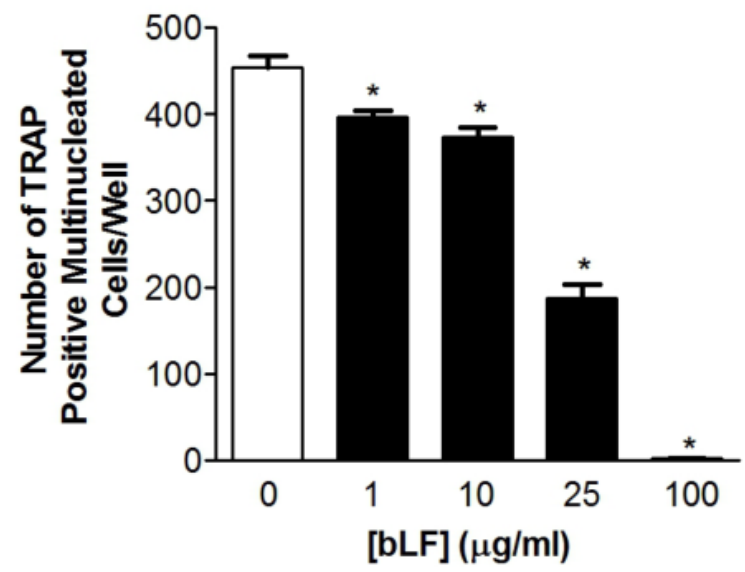

Fig. 5. Inhibition of osteoclastogenesis by lactoferrin in mouse bone marrow cultures

\subsection{Structure/Function relationship of lactoferrin's bone activity}

Bovine, human and recombinant forms of lactoferrin have comparable ability in stimulating osteoblast proliferation (Cornish et al. 2004). This suggests that glycosylation is not critical to the mitogenic activity as these three forms of lactoferrin are differentially glycosylated. Furthermore, when carbohydrate chains were removed from bovine lactoferrin, the aglycoform was as potent as the glyco-form (Cornish et al. 2006), confirming that carbohydrate is not a major determinant in the mitogenic activity of lactoferrin in osteoblasts. The activity of lactoferrin on bone cells was also shown to be independent of iron-binding with apo-, native and holo- preparations of bovine lactoferrin giving similar levels of stimulation of proliferation (Cornish et al. 2006). Moreover, replacement of the iron with chromium and manganese, two transition metals of equivalent size, also had no effect. This suggests firstly that the conformational changes induced by iron-binding have no impact on lactoferrin activity, and secondly that bound iron is not essential to this activity.

Further structure/function studies were performed using the N-lobe and C-lobe of bovine lactoferrin (prepared by proteolysis), the N-lobe of human lactoferrin (prepared by recombinant technology), and synthetic bovine lactoferricin peptides (Cornish et al. 2006). The N-lobes of both human and bovine lactoferrin and the C-lobe of bovine lactoferrin all showed osteogenic activity as measured by proliferation of primary rat osteoblasts, but the magnitude of response was less than for the full length molecule (Fig 6A). Interestingly, the bovine C-lobe appeared to have a stronger effect on proliferation than the bovine N-lobe. The bovine lactoferricin peptides (17-31 \& 20-30) were both mildly osteogenic (Fig 6B). The Nlobe of human lactoferrin decreased osteoclastogenesis in a dose-dependent manner with an 
activity that appeared to be equivalent, on a molar basis, to that of intact recombinant human lactoferrin. In contrast, the C-lobe of bovine lactoferrin has only a weak effect in this assay. The ability of the various lactoferrin lobes and fragments to influence both osteoblast proliferation and osteoclast development suggests that several sites on the lactoferrin molecule might be involved in receptor recognition, binding and stabilisation, or alternatively, more than one receptor might be involved. On a molar basis, the activity of intact lactoferrin on bone cell proliferation was at least 10 -fold greater than that of the part molecules, which suggests that a global structure is required for optimal activity. In contrast, the equivalent osteoclastogenic activities of the recombinant human lactoferrin and its N-lobe suggest that this activity might be largely located in the N-lobe. However, further structure/function studies are warranted, as from a therapeutic perspective small active synthetic peptides might present a more attractive option for drug development than the intact lactoferrin molecule.

A

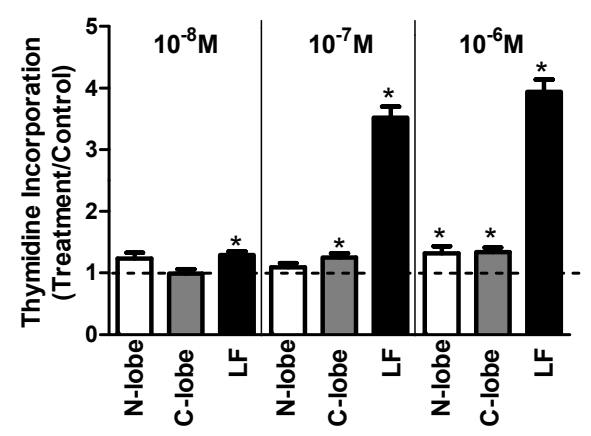

B

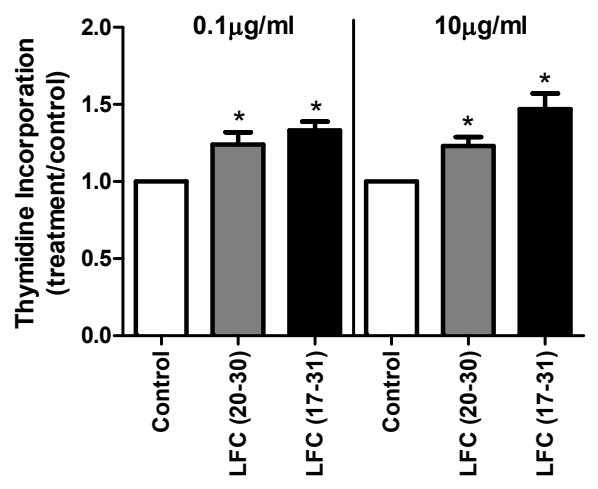

Fig. 6. Thymidine incorporation in primary rat osteoblasts treated with lactoferrin fragments. LF; intact lactoferrin, LFC; lactoferricin.

\subsection{Lactoferrin's activity in bone in vivo}

A number of recently published studies tested the potential use of lactoferrin for protection against bone loss. The effect of dietary supplementation of lactoferrin on bone was measured using ovariectomized (OVX) rodents as a model for post menopausal bone loss (Blais et al. 2009; Guo et al. 2009; Malet et al. 2011). C3H mice that were either OVX or sham operated, received a control diet or the same diet supplemented with different concentrations of bovine lactoferrin for 27 weeks. Lactoferrin supplementation improved bone mineral density and bone strength, measured as femoral failure load, in a dosedependent manner (Blais et al. 2009). A study in OVX rats produced similar results. Lactoferrin orally administered to OVX rats for 3 months protected them against the OVXinduced reduction of bone volume and bone mineral density and increased the parameters of mechanical strength. Measurements of biochemical markers of bone remodelling indicated greater bone formation and reduced bone resorption occurred in rats treated with lactoferrin (Guo et al. 2009). Yamano et al. (Yamano et al. 2010) studied the potential use of lactoferrin for the prevention of alveolar bone destruction associated with periodontitis in an LPS-induced periodontitis rat model. Lactoferrin or liposomal-lactoferrin, which 
improved the robustness of bovine lactoferrin to digestive enzymes, were added to the drinking water for 7 days. The study showed that bone resorption stimulated by LPS through activation of TNF-a production and modulation of RANKL/OPG balance in osteoblasts was inhibited by the orally administered lactoferrin. The researchers suggest that liposomal-lactoferrin could be a potent therapeutic and preventive agent for attenuating alveolar bone destruction in periodontitis patients.

In a small clinical study, 38 healthy postmenopausal women were randomized to receive placebo or a ribonuclease-enriched lactoferrin dietary supplement (Bharadwaj et al. 2009). In the lactoferrin-treated group there was a decrease in the bone resorption markers urine deoxypyridinoline (Dpd) crosslinks and serum N-telopeptides and an increase in the bone formation markers bone-specific alkaline phosphatase and osteocalcin, but the results are difficult to interpret due to differences in the levels of markers between the two groups before treatment.

\subsection{The expression of lactoferrin in bone and cartilage}

Investigations of the expression of lactoferrin in normal fetal and adult bone and cartilage by immunohistochemistry determined that fetal chondroblasts and osteoblasts are positive for lactoferrin immunoreactivity, whereas the corresponding adult cells are negative (Antonio et al. 2010; Ieni et al. 2009a; 2009b; 2011). Bone and cartilaginous specimens from fetuses at 8-34 weeks of gestation were studied. At the eighth gestational week, lactoferrin immunoreactivity was mainly present in the mesenchymal cells forming the periosteum and in chondroblasts; and a lactoferrin signal was also present in immature osteocytes and osteoblasts up to the 18th gestation week. The lactoferrin immunoreactivity decreased considerably by the 24th week, with no expression found in any bone area after the 30th week or in any samples from adult bone (Antonio et al. 2010; Ieni et al. 2011). The expression of lactoferrin in bone and cartilaginous tissue between 8 and 24 weeks of gestation suggests a possible role for lactoferrin as a bone growth regulator in the early phases of the human endochondral ossification.

The expression of lactoferrin was also studied by immunohistochemistry in a large number of tumors of bone and cartilage (Ieni et al. 2009a; 2009b; 2011). About half of all cases of osteocartilagineous tumors were positive, with lactoferrin expression in all giant cell tumors tested, all chondroblastomas, chondromyxoid fibromas and most osteoid osteomas. No lactoferrin immunoexpression was detected in osteosarcomas, chondrosarcomas, ossifying fibromas, osteochondroma and enchondromas. It is possible that lactoferrin expression reflects a less mature phenotype of these tumors, as lactoferrin is absent from normal adult bone and cartilage tissues.

\subsection{Lactoferrin as a therapeutic agent}

\subsubsection{Local delivery}

There is much interest in the potential use of lactoferrin as a factor that can act locally in topical applications for regenerative bone therapies and bone tissue engineering. Various biomaterials and biomedical devices have been used to improve delivery and enable sustained release of lactoferrin at the requisite site. Bovine lactoferrin incorporated into a type 1 collagen membrane promoted bone-like tissue formation by MG63 cells which were plated over the membrane (Takayama \& Mizumachi 2009) and implantation of biodegradable gelatin hydrogels incorporating lactoferrin into a skull bone defect of rats 
resulted in significantly stronger bone regeneration at the defect than was observed in either lactoferrin-free- or low-lactoferrin-treated rats (Takaoka et al. 2011). It was concluded that the sustained release from the gelatin hydrogels enabled lactoferrin to enhance the in vivo activity of bone regeneration. A titanium bone plate carrying lactoferrin for treatment of metaphyseal fracture has been patented, primarily as an implant for antibiosis, but such a device could conceivably be used for the promotion of bone repair (Fei et al. 2008). In the same context, a recent technology has been described whereby lactoferrin was coated in thin films onto inert substrates such as silica and biocompatibility assessed for use in applications such as implants (Constantinescu et al. 2009).

\subsubsection{Oral delivery}

The potential use of lactoferrin as a food supplement that promotes bone health requires experimental evidence showing that it is active when administered orally. Most ingested proteins are degraded into oligopeptides and amino acids in the small intestine and then absorbed as nutrients. The digestion of lactoferrin was studied in adult mice and rats (Fischer et al. 2007; Kuwata et al. 2001). In mice, immunoreactive lactoferrin, measured by ELISA one hour following intragastric intubation of a single dose, was present at the highest concentrations in the stomach, and in lower concentrations in all segments of the intestine: proximal intestine, distal intestine, caecum and large bowel (Fischer et al. 2007). Oral administration of 125 I-labelled lactoferrin in adult rats, followed by detection of multiple forms of degraded lactoferrin by surface-enhanced laser desorption/ionization (SELDI) affinity mass spectrometry showed that the bioactive fragment lactoferricin (17-42) could survive proteolytic degradation in the small intestine (Kuwata et al. 2001).

Transport of intact lactoferrin from the gut lumen to the circulation has been shown in infants (Hutchens et al. 1989, 1991; Knapp \& Hutchens 1994) young calves (Talukder et al. 2002, 2003) and piglets (Harada et al. 1999) suggesting that as the selective transport from the gut is not yet fully developed macromolecules can cross into the circulation. In addition, a number of recent studies demonstrated transport of intact lactoferrin in adult animals and in humans. Fischer et al. (Fischer et al. 2007) found that 10 minutes after the administration of $1 \mathrm{mg}$ lactoferrin to adult mice through intragastric intubation, the intact molecule could be detected in the peripheral blood as well as in the liver, kidneys, gall bladder, spleen and brain. Transport of lactoferrin into the circulation has also been shown in groups of Ovx mice that were fed different concentrations of bovine lactoferrin $(1-20 \mathrm{~g} / \mathrm{kg})$ for 27 weeks. Blood concentrations of immunoreactive lactoferrin of mice that received the bovine lactoferrin-supplemented diets were significantly increased compared to controls and were correlated to the bovine lactoferrin concentration in the diet (Blais et al. 2009).

\subsubsection{Functional foods}

An important consideration for the use of food systems as vehicles for bioactive delivery is that the bioactive remains active throughout manufacture and shelf-life of the product. Recent work has shown that bovine lactoferrin dosed into stirred yoghurt remained structurally intact and retained its osteogenic activity on primary bone-forming cells up to 21 days after storage of the yoghurt at $4^{\circ} \mathrm{C}$ (Palmano et al. 2011). In many respects yoghurt is the ideal functional food matrix for bone as it is calcium rich and a popular consumer product. 


\subsubsection{Lactoferrin preparations with potential use for bone applications}

Bovine and human lactoferrin constitute the most studied of the lactoferrins. In general and in spite of some structural differences, bovine and human lactoferrin including recombinant forms appear to have comparable bioactivities. However, some differences between bovine lactoferrin and human lactoferrin have been noted with respect to intestinal receptor recognition (Kawakami \& Lonnerdal 1991) and it cannot be assumed that activities are always interchangeable

The use of lactoferrin as a therapeutic agent requires not only proof of efficacy at the clinical level, but assured safety, consistent quality of supply and appropriate delivery mechanisms. Most studies on the effects of lactoferrin on bone, including clinical trials, have been performed using bovine lactoferrin. Bovine lactoferrin from milk has been available as a commercial isolate for many years (Tomita et al. 2009). It has a 'Generally Recognized As Safe' (GRAS) status from the United States Food and Drug Administration (FDA) and now has widespread acceptance for oral use in humans. Indeed, it has been available for a number of years in Japan and other countries as a dietary supplement and as a functional ingredient in foods such as yoghurt and fortified infant formulae (Wakabayashi \& Tasaki 2006). Bovine lactoferrin has been administered orally at doses of $3 \mathrm{~g} /$ day for one year in a cancer clinical trial, with some positive outcomes and no apparent adverse effects (Tomita et al. 2009).

Equally, recombinant human lactoferrin can be considered for oral application although to date there have been no oral efficacy clinical trials targeted specifically at bone. High expression levels can be achieved in rice (Nandi et al. 2005) and transgenic animals (van Berkel et al. 2002) and recombinant human lactoferrin expressed in both baby kidney hamster cells and rice has been shown to have comparable activity to human lactoferrin and bovine lactoferrin in stimulating proliferation of primary rat osteoblasts (Cornish et al. 2004; Huang et al. 2008). Rice recombinant human lactoferrin was shown to have no toxicity in rats when administered up to $1000 \mathrm{mg} / \mathrm{kg}$ body weight/day for 28 days (Bethell et al. 2008a, $2008 \mathrm{~b}$ ) and did not elicit an allergic response in plant-glycan sensitive humans in a limited clinical study (Mari et al. 2008). Moreover it was shown to have beneficial effects as an oral agent in a clinical trial targeted at reduction of diarrhoea in Peruvian children (Zavaleta et al. 2007). No adverse events were reported.

Another potential candidate for bone interventions is Talactoferrin alpha, a proprietary recombinant human lactoferrin expressed in the fungus Aspergillus awamori and produced at industrial scale by Aggenix AG (Sanchez et al. 2010). Talactoferrin is currently being evaluated for the oral treatment of several cancer types and Fast Track designation has been granted to Agennix by the FDA for treatment of non-small cell lung cancer (NSCLC) and first-line treatment of renal carcinoma in combination with sunitinib. Placebo-controlled Phase II clinical trials have been successfully completed for NSCLC (Jonasch et al. 2008) and at time of writing two Phase III trials evaluating Talactoferrin in NSCLC patients are ongoing. Talactoferrin appears to have no toxicity, is well tolerated and also appears to be safe for topical applications. It has shown efficacy in the local treatment of diabetic ulcers (Engelmayer et al. 2008) for which it also has Fast Track FDA approval (Sanchez et al. 2010).

\section{Conclusion}

The positive effects of lactoferrin in bone have been demonstrated in vitro; where lactoferrin induces osteoblast proliferation, survival and differentiation and inhibits osteoclast formation, and in vivo; where lactoferrin given as a dietary supplement to rat and mice 
protects against bone loss associated with oestrogen deficiency. The molecular pathways activated by lactoferrin in bone cells are only partially understood, and it appears that a combination of direct and indirect physiological mechanisms is producing the overall anabolic effect of lactoferrin in bone. Pharmaceutical or nutriceutical use of lactoferrin would require the development of a preparation with assured safety and consistent quality of supply. A better understanding of lactoferrin's mechanism of action in bone would allow for the design of compounds that can mimic its anabolic bone activity, and would be useful in pathological states of reduced bone quality in either systemic or local applications.

\section{References}

Antonio, I., Valeria, B., Maddalena, G. \& Giovanni, T. (2010). Immunohistochemical evidence of lactoferrin in human embryo-fetal bone and cartilage tissues. Cell Biol Int 34(8): 845-849.

Baker, E. N. (1994). Structure and reactivity of transferrins. Adv Inorg Chem 41: 389-463.

Baker, E. N. \& Baker, H. M. (2005). Molecular structure, binding properties and dynamics of lactoferrin. Cell Mol Life Sci 62(22): 2531-2539.

Baker, E. N. \& Baker, H. M. (2009). A structural framework for understanding the multifunctional character of lactoferrin. Biochimie 91(1): 3-10.

Baldwin, D. A., Jenny, E. R. \& Aisen, P. (1984). The effect of human serum transferrin and milk lactoferrin on hydroxyl radical formation from superoxide and hydrogen peroxide. J Biol Chem 259(21): 13391-13394.

Bellamy, W., Takase, M., Yamauchi, K., Wakabayashi, H., Kawase, K. \& Tomita, M. (1992). Identification of the bactericidal domain of lactoferrin. Biochimt Biophys Acta 1121(12): 130-136.

Bethell, D., Cerven, D. \& DeGeorge, G. (2008a). 28-day repeated dose oral toxicity of recombinant human apo-lactoferrin or recombinant human lysozyme in rats. Regul Toxicol Pharm 51(2): 162-167.

Bethell, D., Cerven, D. \& DeGeorge, G. (2008b). 28-Day repeated dose oral toxicity of recombinant human holo-lactoferrin in rats. Regul Toxicol Pharm 52(2): 174-179.

Bezwoda, W. R. \& Mansoor, N. (1989). Lactoferrin from human breast milk and from neutrophil granulocytes. Comparative studies of isolation, quantitation, characterization and iron binding properties. Biomed Chromatog 3(3): 121-126.

Bharadwaj, S., Naidu, A. G., Betageri, G. V., Prasadarao, N. V. \& Naidu, A. S. (2009). Milk ribonuclease-enriched lactoferrin induces positive effects on bone turnover markers in postmenopausal women. Osteoporos Int 20(9): 1603-1611.

Blais, A., Malet, A., Mikogami, T., Martin-Rouas, C. \& Tome, D. (2009). Oral bovine lactoferrin improves bone status of ovariectomized mice. Am J Physiol Endocrinol Metab 296(6): E1281-1288.

Bournazou, I., Mackenzie, K. J., Duffin, R., Rossi, A. G. \& Gregory, C. D. (2010). Inhibition of eosinophil migration by lactoferrin. Immunol Cell Biol 88(2): 220-223.

Bournazou, I., Pound, J. D., Duffin, R., Bournazos, S., Melville, L. A., Brown, S. B., Rossi, A. G. \& Gregory, C. D. (2009). Apoptotic human cells inhibit migration of granulocytes via release of lactoferrin. J Clin Invest 119(1): 20-32.

Brock, J. H. (2002). The physiology of lactoferrin. Biochem Cell Biol 80(1): 1-6.

Brock, J. H., Arzabe, F., Lampreave, F. \& Pineiro, A. (1976). The effect of trypsin on bovine transferrin and lactoferrin. Biochim Biophys Acta 446(1): 214-225. 
Caccavo, D., Sebastiani, G. D., Di Monaco, C., Guido, F., Galeazzi, M., Ferri, G. M., Bonomo, L. \& Afeltra, A. (1999). Increased levels of lactoferrin in synovial fluid but not in serum from patients with rheumatoid arthritis. Int J Clin Lab Res 29(1): 30-35.

Constantinescu, C., Palla-Papavlu, A., Rotaru, A., Florian, P., Chelu, F., Icriverzi, M., Nedelcea, A., Dinca, V., Roseanu, A. \& Dinescu, M. (2009). Multifunctional thin films of lactoferrin for biochemical use deposited by MAPLE technique. Appl Surf Sci 255(10): 5491-5495.

Cornish, J., Balchin, L. M., Callon, K. E., Grey, A. B., Cooper, G. J. \& Reid, I. R. (2000). Amylin and adrenomedullin - novel promotors of osteoblast survival from apoptosis. Bone 27: 19S.

Cornish, J., Callon, K. E., Coy, D. H., Jiang, N. Y., Xiao, L., Cooper, G. J. \& Reid, I. R. (1997a). Adrenomedullin is a potent stimulator of osteoblastic activity in vitro and in vivo. Am J Physiol 273(6 Pt 1): E1113-1120.

Cornish, J., Callon, K. E., Lin, C. Q., Xiao, C. L., Gamble, G. D., Cooper, G. J. \& Reid, I. R. (1999). Comparison of the effects of calcitonin gene-related peptide and amylin on osteoblasts. J Bone Miner Res 14(8): 1302-1309.

Cornish, J., Callon, K. E., Naot, D., Palmano, K. P., Banovic, T., Bava, U., Watson, M., Lin, J. M., Tong, P. C., Chen, Q., Chan, V. A., Reid, H. E., Fazzalari, N., Baker, H. M., Baker, E. N., Haggarty, N. W., Grey, A. B. \& Reid, I. R. (2004). Lactoferrin is a potent regulator of bone cell activity and increases bone formation in vivo. Endocrinology 145(9): 4366-4374.

Cornish, J., Callon, K. E., Nicholson, G. C. \& Reid, I. R. (1997b). Parathyroid hormone-related protein-(107-139) inhibits bone resorption in vivo. Endocrinology 138(3): 1299-1304.

Cornish, J., Callon, K. E. \& Reid, I. R. (1995). An in vivo model for the rapid assessment of the local effects of parathyroid hormone on bone histomorphometry. Bone 17(4 Suppl): 249S-254S.

Cornish, J., Callon, K. E. \& Reid, I. R. (1996). Insulin increases histomorphometric indices of bone formation In vivo. Calcif Tissue Int 59(6): 492-495.

Cornish, J. \& Naot, D. (2010). Lactoferrin as an effector molecule in the skeleton. Biometals 23(3): 425-430.

Cornish, J., Palmano, K., Callon, K. E., Watson, M., Lin, J. M., Valenti, P., Naot, D., Grey, A. B. \& Reid, I. R. (2006). Lactoferrin and bone; structure-activity relationships. Biochem Cell Biol 84(3): 297-302.

Derisbourg, P., Wieruszeski, J. M., Montreuil, J. \& Spik, G. (1990). Primary Structure of Glycans Isolated from Human-Leukocyte Lactotransferrin - Absence of Fucose Residues Questions the Proposed Mechanism of Hyposideremia. Biochem J 269(3): 821-825.

Engelmayer, J., Blezinger, P. \& Varadhachary, A. (2008). Talactoferrin stimulates wound healing with modulation of inflammation. J Surg Res 149(2): 278-286.

Fei, J., Yu, H., Wang, A., Zhao, C. \& Pan, Z. (2008). Bone plate for carrying and releasing antibacterial peptide comprises titanium or titanium alloy material having hydroxy phosphorite coating on its surface, where outer surface of coating has betadefensins or lactoferrin.

Fischer, R., Debbabi, H., Blais, A., Dubarry, M., Rautureau, M., Boyaka, P. N. \& Tome, D. (2007). Uptake of ingested bovine lactoferrin and its accumulation in adult mouse tissues. Int Immunopharmacol 7(10): 1387-1393. 
Gahr, M., Speer, C. P., Damerau, B. \& Sawatzki, G. (1991). Influence of lactoferrin on the function of human polymorphonuclear leukocytes and monocytes. J Leukoc Biol 49(5): 427-433.

Gonzalez-Chavez, S. A., Arevalo-Gallegos, S. \& Rascon-Cruz, Q. (2009). Lactoferrin: structure, function and applications. Int J Antimicrob Agents 33(4): 301 e301-308.

Grey, A., Banovic, T., Zhu, Q., Watson, M., Callon, K., Palmano, K., Ross, J., Naot, D., Reid, I. R. \& Cornish, J. (2004). The low-density lipoprotein receptor-related protein 1 is a mitogenic receptor for lactoferrin in osteoblastic cells. Mol Endocrinol 18(9): 2268-2278.

Grey, A., Zhu, Q., Watson, M., Callon, K. \& Cornish, J. (2006). Lactoferrin potently inhibits osteoblast apoptosis, via an LRP1-independent pathway. Mol Cell Endocrinol 251(12): 96-102.

Groves, M. L., Basch, J. J. \& Gordon, W. G. (1963). Isolation, Characterization, and Amino Acid Composition of a New Crystalline Protein, Lactollin, from Milk. Biochemistry 2: 814-817.

Guo, H. Y., Jiang, L., Ibrahim, S. A., Zhang, L., Zhang, H., Zhang, M. \& Ren, F. Z. (2009). Orally administered lactoferrin preserves bone mass and microarchitecture in ovariectomized rats. J Nutr 139(5): 958-964.

Hangoc, G., Falkenburg, J. H. \& Broxmeyer, H. E. (1991). Influence of T-lymphocytes and lactoferrin on the survival-promoting effects of IL- 1 and IL-6 on human bone marrow granulocyte-macrophage and erythroid progenitor cells. Exp Hematol 19(7): 697-703.

Harada, E., Itoh, Y., Sitizyo, K., Takeuchi, T., Araki, Y. \& Kitagawa, H. (1999). Characteristic transport of lactoferrin from the intestinal lumen into the bile via the blood in piglets. Comp Biochem Physiol A Mol Integr Physiol 124(3): 321-327.

He, J. \& Furmanski, P. (1995). Sequence specificity and transcriptional activation in the binding of lactoferrin to DNA. Nature 373(6516): 721-724.

Huang, N., Bethell, D., Card, C., Cornish, J., Marchbank, T., Wyatt, D., Mabery, K. \& Playford, R. (2008). Bioactive recombinant human lactoferrin, derived from rice, stimulates mammalian cell growth. In Vitro Cell Dev Biol Anim 44(10): 464-471.

Hutchens, T. W., Henry, J. F. \& Yip, T. T. (1989). Purification and characterization of intact lactoferrin found in the urine of human milk-fed preterm infants. Clin Chem 35(9): 1928-1933.

Hutchens, T. W., Henry, J. F. \& Yip, T. T. (1991). Structurally intact (78-kDa) forms of maternal lactoferrin purified from urine of preterm infants fed human milk: identification of a trypsin-like proteolytic cleavage event in vivo that does not result in fragment dissociation. Proc Natl Acad Sci U S A 88(8): 2994-2998.

Ieni, A., Barresi, V., Grosso, M., Rosa, M. A. \& Tuccari, G. (2009a). Immunolocalization of lactoferrin in cartilage-forming neoplasms. J Orthop Sci 14(6): 732-737.

Ieni, A., Barresi, V., Grosso, M., Rosa, M. A. \& Tuccari, G. (2009b). Lactoferrin immunoexpression in human normal and neoplastic bone tissue. J Bone Miner Metab 27(3): 364-371.

Ieni, A., Barresi, V., Grosso, M., Speciale, G., Rosa, M. A. \& Tuccari, G. (2011). Does lactoferrin behave as an immunohistochemical oncofetal marker in bone and cartilage human neoplasms? Pathol Oncol Res 17(2): 287-293.

Jenssen, H. \& Hancock, R. E. (2009). Antimicrobial properties of lactoferrin. Biochimie 91(1): 19-29.

Ji, Z. S. \& Mahley, R. W. (1994). Lactoferrin binding to heparan sulfate proteoglycans and the LDL receptor-related protein. Further evidence supporting the importance of direct 
binding of remnant lipoproteins to HSPG. Arteriosclerosis and Thrombosis 14(12): 2025-2031.

Jonasch, E., Stadler, W. M., Bukowski, R. M., Hayes, T. G., Varadhachary, A., Malik, R., Figlin, R. A. \& Srinivas, S. (2008). Phase 2 trial of talactoferrin in previously treated patients with metastatic renal cell carcinoma. Cancer 113(1): 72-77.

Kanwar, J. R., Burrow, H. \& Kanwar, R. K. (2011). Antioxidant Enzyme Activities of IronSaturated Bovine Lactoferrin (Fe-bLf) in Human Gut Epithelial Cells Under Oxidative Stress. Med Chem 7(3): 224-230.

Kawakami, H. \& Lonnerdal, B. (1991). Isolation and function of a receptor for human lactoferrin in human fetal intestinal brush-border membranes. Am J Physiol 261(5 Pt 1): G841-846.

Kim, W. S., Shimazaki, K. \& Tamura, T. (2006). Expression of bovine lactoferrin C-lobe in Rhodococcus erythropolis and its purification and characterization. Biosci Biotechnol Biochem 70(11): 2641-2645.

Knapp, R. D. \& Hutchens, T. W. (1994). Maternal lactoferrin in the urine of preterm infants. Evidence for retention of structure and function. Adv Exp Med Biol 357: 177-181.

Kuwata, H., Yamauchi, K., Teraguchi, S., Ushida, Y., Shimokawa, Y., Toida, T. \& Hayasawa, H. (2001). Functional fragments of ingested lactoferrin are resistant to proteolytic degradation in the gastrointestinal tract of adult rats. J Nutr 131(8): 2121-2127.

Legrand, D., Elass, E., Carpentier, M. \& Mazurier, J. (2005). Lactoferrin: a modulator of immune and inflammatory responses. Cell Mol Life Sci 62(22): 2549-2559.

Legrand, D., Elass, E., Carpentier, M. \& Mazurier, J. (2006). Interactions of lactoferrin with cells involved in immune function. Biochem Cell Biol 84(3): 282-290.

Legrand, D. \& Mazurier, J. (2010). A critical review of the roles of host lactoferrin in immunity. Biometals 23(3): 365-376.

Legrand, D., Vigie, K., Said, E. A., Elass, E., Masson, M., Slomianny, M. C., Carpentier, M., Briand, J. P., Mazurier, J. \& Hovanessian, A. G. (2004). Surface nucleolin participates in both the binding and endocytosis of lactoferrin in target cells. Eur J Biochem 271(2): 303-317.

Lonnerdal, B., Keen, C. L. \& Hurley, L. S. (1985). Manganese binding proteins in human and cow's milk. Am J Clin Nutr 41(3): 550-559.

Lorget, F., Clough, J., Oliveira, M., Daury, M. C., Sabokbar, A. \& Offord, E. (2002). Lactoferrin reduces in vitro osteoclast differentiation and resorbing activity. Biochem Biophys Res Commun 296(2): 261-266.

Malet, A., Bournaud, E., Lan, A., Mikogami, T., Tome, D. \& Blais, A. (2011). Bovine lactoferrin improves bone status of ovariectomized mice via immune function modulation. Bone 48(5): 1028-1035.

Mann, D. M., Romm, E. \& Migliorini, M. (1994). Delineation of the glycosaminoglycanbinding site in the human inflammatory response protein lactoferrin. J Biol Chem 269(38): 23661-23667.

Mari, A., Ooievaar-de Heer, P., Scala, E., Giani, M., Pirrotta, L., Zuidmeer, L., Bethell, D. \& van Ree, R. (2008). Evaluation by double-blind placebo-controlled oral challenge of the clinical relevance of IgE antibodies against plant glycans. Allergy 63(7): 891-896.

Matsue, M., Matsuyama, J. \& Kiyosawa, I. (1995). Interaction of lactoferrin with ascorbate and the relationship with bleomycin-dependent DNA damage. Biosci Biotechnol Biochem 59(3): 358-362. 
Mir, R., Kumar, R. P., Singh, N., Vikram, G. P., Sinha, M., Bhushan, A., Kaur, P., Srinivasan, A., Sharma, S. \& Singh, T. P. (2010). Specific interactions of C-terminal half (C-lobe) of lactoferrin protein with edible sugars: binding and structural studies with implications on diabetes. Int J Biol Macromol 47(1): 50-59.

Moguilevsky, N., Retegui, L. A. \& Masson, P. L. (1985). Comparison of human lactoferrins from milk and neutrophilic leucocytes. Relative molecular mass, isoelectric point, iron-binding properties and uptake by the liver. Biochem J 229(2): 353-359.

Nakajima, K. I., Kanno, Y., Nakamura, M., Gao, X. D., Kawamura, A., Itoh, F. \& Ishisaki, A. (2011). Bovine milk lactoferrin induces synthesis of the angiogenic factors VEGF and FGF2 in osteoblasts via the p44/p42 MAP kinase pathway. Biometals.

Nandi, S., Yalda, D., Lu, S., Nikolov, Z., Misaki, R., Fujiyama, K. \& Huang, N. (2005). Process development and economic evaluation of recombinant human lactoferrin expressed in rice grain. Transgenic Res 14(3): 237-249.

Naot, D., Chhana, A., Matthews, B. G., Callon, K. E., Tong, P. C., Lin, J. M., Costa, J. L., Watson, M., Grey, A. B. \& Cornish, J. (2011). Molecular mechanisms involved in the mitogenic effect of lactoferrin in osteoblasts. Bone 49(2): 217-224.

Paesano, R., Pietropaoli, M., Gessani, S. \& Valenti, P. (2009). The influence of lactoferrin, orally administered, on systemic iron homeostasis in pregnant women suffering of iron deficiency and iron deficiency anaemia. Biochimie 91(1): 44-51.

Palmano, K. P., Ramos, R., Watson, M., Callon, K. E. \& Cornish, J. (2011). Survival and boneactive properties of bovine lactoferrin supplemented into stirred yoghurt. Int Dairy J 21: 477-483.

Pierce, A., Colavizza, D., Benaissa, M., Maes, P., Tartar, A., Montreuil, J. \& Spik, G. (1991). Molecular cloning and sequence analysis of bovine lactotransferrin. Eur J Biochem 196(1): 177-184.

Raghuveer, T. S., McGuire, E. M., Martin, S. M., Wagner, B. A., Rebouche, C. J., Buettner, G. R. \& Widness, J. A. (2002). Lactoferrin in the preterm infants' diet attenuates ironinduced oxidation products. Pediatr Res 52(6): 964-972.

Sanchez, L., Conesa, C. \& Calvo, M. (2010). Recombinant human lactoferrin: A valuable protein for pharmaceutical products and functional foods. Biotechnol Adv 28(6): 831-838.

Shinoda, I., Takase, M., Fukuwatari, Y., Shimamura, S., Koller, M. \& Konig, W. (1996). Effects of lactoferrin and lactoferricin on the release of interleukin 8 from human polymorphonuclear leukocytes. Biosci Biotechnol Biochem 60(3): 521-523.

Siciliano, R., Rega, B., Marchetti, M., Seganti, L., Antonini, G. \& Valenti, P. (1999). Bovine lactoferrin peptidic fragments involved in inhibition of herpes simplex virus type 1 infection. Biochem Biophys Res Commun 264(1): 19-23.

Smith, C. A., Ainscough, E. W., Baker, H. M., Brodie, A. M. \& Baker, E. N. (1994). Specific Binding of Cerium by Human Lactoferrin Stimulates the Oxidation of Ce3+ to Ce4+. . J Am Chem Soc 116: 7889-7890.

Sorimachi, K., Akimoto, K., Hattori, Y., Ieiri, T. \& Niwa, A. (1997). Activation of macrophages by lactoferrin: secretion of TNF-alpha, IL-8 and NO. Biochem Mol Biol Int 43(1): 79-87.

Takaoka, R., Hikasa, Y., Hayashi, K. \& Tabata, Y. (2011). Bone Regeneration by Lactoferrin Released from a Gelatin Hydrogel. J Biomater Sci Polym Ed 22(12): 1581-1589.

Takayama, Y. \& Mizumachi, K. (2008). Effect of bovine lactoferrin on extracellular matrix calcification by human osteoblast-like cells. Biosci Biotechnol Biochem 72(1): 226-230. 
Takayama, Y. \& Mizumachi, K. (2009). Effect of lactoferrin-embedded collagen membrane on osteogenic differentiation of human osteoblast-like cells. J Biosci Bioeng 107(2): 191-195.

Talukder, M. J., Takeuchi, T. \& Harada, E. (2002). Transport of colostral macromolecules into the cerebrospinal fluid via plasma in newborn calves. J Dairy Sci 85(3): 514-524.

Talukder, M. J., Takeuchi, T. \& Harada, E. (2003). Receptor-mediated transport of lactoferrin into the cerebrospinal fluid via plasma in young calves. J Vet Med Sci 65(9): 957-964.

Tomita, M., Wakabayashi, H., Shin, K., Yamauchi, K., Yaeshima, T. \& Iwatsuki, K. (2009). Twenty-five years of research on bovine lactoferrin applications. Biochimie 91(1): 52-57.

Troost, F. J., Steijns, J., Saris, W. H. \& Brummer, R. J. (2001). Gastric digestion of bovine lactoferrin in vivo in adults. J Nutr 131(8): 2101-2104.

van Berkel, P. H., Geerts, M. E., van Veen, H. A., Mericskay, M., de Boer, H. A. \& Nuijens, J. H. (1997). N-terminal stretch Arg2, Arg3, Arg4 and Arg5 of human lactoferrin is essential for binding to heparin, bacterial lipopolysaccharide, human lysozyme and DNA. Biochem J 328 ( Pt 1): 145-151.

van Berkel, P. H., Welling, M. M., Geerts, M., van Veen, H. A., Ravensbergen, B., Salaheddine, M., Pauwels, E. K., Pieper, F., Nuijens, J. H. \& Nibbering, P. H. (2002). Large scale production of recombinant human lactoferrin in the milk of transgenic cows. Nat Biotechnol 20(5): 484-487.

van der Kraan, M. I., Groenink, J., Nazmi, K., Veerman, E. C., Bolscher, J. G. \& Nieuw Amerongen, A. V. (2004). Lactoferrampin: a novel antimicrobial peptide in the N1domain of bovine lactoferrin. Peptides 25(2): 177-183.

Vasilyev, V. B. (2010). Interactions of caeruloplasmin with other proteins participating in inflammation. Biochem Soc Trans 38(4): 947-951.

Wakabayashi, H. Y., K. \& Tasaki, M. (2006). Lactoferrin research, technology and applications. Int Dairy J 16: 1241-1252.

Willnow, T. E., Goldstein, J. L., Orth, K., Brown, M. S. \& Herz, J. (1992). Low density lipoprotein receptor-related protein and gp330 bind similar ligands, including plasminogen activator-inhibitor complexes and lactoferrin, an inhibitor of chylomicron remnant clearance. J Biol Chem 267(36): 26172-26180.

Yagi, M., Suzuki, N., Takayama, T., Arisue, M., Kodama, T., Yoda, Y., Otsuka, K. \& Ito, K. (2009). Effects of lactoferrin on the differentiation of pluripotent mesenchymal cells. Cell Biol Int 33(3): 283-289.

Yamano, E., Miyauchi, M., Furusyo, H., Kawazoe, A., Ishikado, A., Makino, T., Tanne, K., Tanaka, E. \& Takata, T. (2010). Inhibitory effects of orally administrated liposomal bovine lactoferrin on the LPS-induced osteoclastogenesis. Lab Invest 90(8): 1236-1246.

Yamniuk, A. P., Burling, H. \& Vogel, H. J. (2009). Thermodynamic characterization of the interactions between the immunoregulatory proteins osteopontin and lactoferrin. Mol Immunol 46(11-12): 2395-2402.

Ying, X., Cheng, S., Wang, W., Lin, Z., Chen, Q., Zhang, W., Kou, D., Shen, Y., Cheng, X., Peng, L., Zi Xu, H. \& Zhu Lu, C. (2011). Effect of lactoferrin on osteogenic differentiation of human adipose stem cells. Int Orthop.

Zavaleta, N., Figueroa, D., Rivera, J., Sanchez, J., Alfaro, S. \& Lonnerdal, B. (2007). Efficacy of rice-based oral rehydration solution containing recombinant human lactoferrin and lysozyme in Peruvian children with acute diarrhea. J Pediatr Gastroenterol Nutr 44(2): 258-264. 


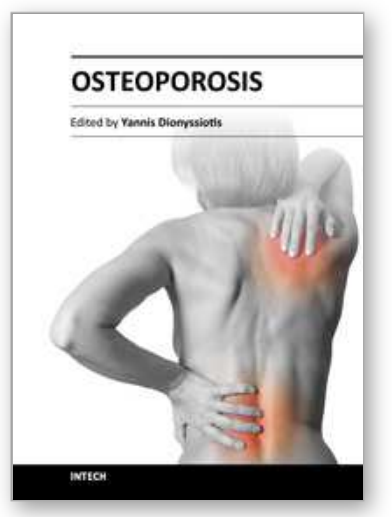

\author{
Osteoporosis \\ Edited by PhD. Yannis Dionyssiotis
}

ISBN 978-953-51-0026-3

Hard cover, 864 pages

Publisher InTech

Published online 24, February, 2012

Published in print edition February, 2012

Osteoporosis is a public health issue worldwide. During the last few years, progress has been made concerning the knowledge of the pathophysiological mechanism of the disease. Sophisticated technologies have added important information in bone mineral density measurements and, additionally, geometrical and mechanical properties of bone. New bone indices have been developed from biochemical and hormonal measurements in order to investigate bone metabolism. Although it is clear that drugs are an essential element of the therapy, beyond medication there are other interventions in the management of the disease. Prevention of osteoporosis starts in young ages and continues during aging in order to prevent fractures associated with impaired quality of life, physical decline, mortality, and high cost for the health system. A number of different specialties are holding the scientific knowledge in osteoporosis. For this reason, we have collected papers from scientific departments all over the world for this book. The book includes up-to-date information about basics of bones, epidemiological data, diagnosis and assessment of osteoporosis, secondary osteoporosis, pediatric issues, prevention and treatment strategies, and research papers from osteoporotic fields.

\title{
How to reference
}

In order to correctly reference this scholarly work, feel free to copy and paste the following:

Dorit Naot, Kate Palmano and Jillian Cornish (2012). Lactoferrin - A Potential Anabolic Intervention in Osteoporosis, Osteoporosis, PhD. Yannis Dionyssiotis (Ed.), ISBN: 978-953-51-0026-3, InTech, Available from: http://www.intechopen.com/books/osteoporosis/lactoferrin-a-potential-anabolic-intervention-inosteoporosis

\section{INTECH}

open science | open minds

\section{InTech Europe}

University Campus STeP Ri

Slavka Krautzeka 83/A

51000 Rijeka, Croatia

Phone: +385 (51) 770447

Fax: +385 (51) 686166

www.intechopen.com

\section{InTech China}

Unit 405, Office Block, Hotel Equatorial Shanghai

No.65, Yan An Road (West), Shanghai, 200040, China 中国上海市延安西路65号上海国际贵都大饭店办公楼 405 单元

Phone: +86-21-62489820

Fax: +86-21-62489821 
(C) 2012 The Author(s). Licensee IntechOpen. This is an open access article distributed under the terms of the Creative Commons Attribution 3.0 License, which permits unrestricted use, distribution, and reproduction in any medium, provided the original work is properly cited. 